\title{
Psychotic symptoms in bipolar disorder: Two years' retrospective study
}

\author{
BR Adhikari, S Mishra, S Nepal, N Sapkota \\ Department of Psychiatry \\ B.P. Koirala Institute of Health Sciences, Dharan
}

\begin{abstract}
Background: Psychosis in bipolar disorder is common but still not well understood. There is paucity of literature from our country and none from this institute which serves the eastern part of Nepal. Objective: To describe the hallucinations and delusions in bipolar disorders in our place. Methods: Patients-record files of bipolar disorders with psychosis discharged in two years' time from 2012 to 2014 were analysed. Patients with unipolar depression, recurrent depressive disorder, serious organic illness, and primary substance use disorders were excluded. Information was collected in a structured performa. Association of delusion and hallucination was observed. Results: During the study period, ninety-five patients with bipolar disorder had psychosis. Hallucination was present in 29 (30.5\%) cases, and out of these 23 (79.3\%) were cases of mania. In 26 (89.7\%) patients, the hallucinations were mood congruent. The median duration of appearance of hallucination was 10 days and appeared early in mania. Among hallucinations, auditory verbal hallucinations were present in all 29 patients. Delusions were present in $77(81.1 \%)$ of patients, and grandiose delusions were the most common. Grandiose delusions tended to occur even in the absence of hallucinations. Conclusion: Psychosis is common in bipolar disorder. Grandiose delusions are the most common delusion and are relatively independent of hallucination. The auditory verbal hallucinations are the most common type of hallucination. Hallucinations in mania tend to manifest earlier than in bipolar depression and mixed episode, and most of the hallucinations in bipolar disorder are mood congruent.
\end{abstract}

Key words: Bipolar disorders, delusion, hallucination, psychosis

\section{Introduction}

Bipolar disorder is a chronic and disabling condition. A patient may present with a manic

\begin{tabular}{l}
\hline Address for correspondence \\
Dr. Baikuntha Raj Adhikari \\
Assistant Professor \\
Department of Psychiatry \\
B.P. Koirala Institute of Health Sciences, Dharan \\
Email: badhi03@gmail.com
\end{tabular}

Address for correspondence

Dr. Baikuntha Raj Adhikari

Department of Psychiatry

Email: badhi03@gmail.com episode, mixed episode, depressive episode, and mixed episode. Any of these episodes may present with psychotic symptoms. Psychotic symptoms in bipolar disorder consists of hallucinations and delusions. ${ }^{1}$ Twenty to fifty per cent of patients suffering 
from a manic episode may exhibit psychotic symptoms. $^{2} \quad$ Some have reported poor outcome in the following one to two years with the presence of psychosis at index episode; ${ }^{3}$ and some have suggested that these patients usually have no mood episodes before index hospitalization. ${ }^{4}$ There are reports of psychosis in prepubertal and adolescent onset bipolar disorder, and authors have hypothesized that psychosis may reflect the severity in childhood and adolescent-onset bipolar disorder. ${ }^{5}$ Looking at the course of bipolar illness as episodic versus chronic, indicated that lifetime history of psychosis was more likely in those with episodic course. ${ }^{6}$ In a study involving 352 patients, it was found that vocational, psychosocial or course of illness were not significantly different between those who had psychotic symptoms and those who did not have psychotic symptoms. ${ }^{7}$ Overall, there are different aspects of psychosis in bipolar disorder. However, one of the essential elements to begin with is the study of phenomenology of psychosis in bipolar disorder, and even though there are few publications of psychosis in bipolar disorder, very little is available from our country. BP Koirala Institute of Health Sciences (BPKIHS) is a tertiary care centre in eastern part of Nepal serving a different sub-population and hence its local findings are also important. The present study attempted to share the phenomenology of hallucinations and delusions in bipolar disorder in this institution.

\section{Methods}

This was a retrospective, descriptive, hospital based study undertaken in BPKIHS, Dharan. All the patients' record files discharged in two years (2012-2014) with the diagnosis of bipolar disorder (irrespective of the index episodes) with psychotic symptoms were included. Unipolar depression and recurrent depressive disorders, absence of psychotic symptoms in bipolar disorder, serious physical or surgical illness, or patients primarily admitted with substance dependence syndrome were excluded. The socio-demographic characteristics, clinical characteristics and psychotic symptoms were recorded in a structured performa prepared by the department for the purpose. The descriptive analyses were done with statistical software SPSS, version -11. Chisquare test was used for association of delusion and hallucination and Mann Whitney test for comparison of median duration of appearance or disappearance of hallucination across diagnostic groups. The level of significance was kept at $<0.05$. The ethical clearance was obtained from the institutional review committee of the institute.

\section{Results}

Socio-demographic parameters are given in table 1. 
Table 1: Socio-demographic variables of bipolar patients with psychotic symptoms $(\mathrm{n}=95)$

\begin{tabular}{|c|c|c|c|c|c|}
\hline Variables & Category & $\begin{array}{l}\text { Total } \\
\text { n (\%) }\end{array}$ & $\begin{array}{c}\text { Manic episode } \\
\text { n (\%) }\end{array}$ & $\begin{array}{l}\text { Pepressive episode } \\
\text { n (\%) }\end{array}$ & $\begin{array}{c}\text { Mixed episode } \\
\text { n (\%) }\end{array}$ \\
\hline \multirow[t]{2}{*}{ Gender } & Male & $59(62.1)$ & $54(62.1)$ & $3(60)$ & $2(66.7)$ \\
\hline & Female & $36(37.9)$ & $33(37.9)$ & $2(40)$ & 1 (33.3) \\
\hline \multirow{4}{*}{$\begin{array}{l}\text { Marital } \\
\text { status }\end{array}$} & Unmarried & $25(26.3)$ & $24(27.6)$ & $1(20)$ & $0(0)$ \\
\hline & Married & $61(64.2)$ & 55 (63.2) & $4(80)$ & $2(66.7)$ \\
\hline & Separated & $7(7.4)$ & $6(6.9)$ & 0 & 1 (33.3) \\
\hline & Widowed & $2(2.1)$ & $2(2.3)$ & $0(0)$ & $0(0)$ \\
\hline \multirow[t]{5}{*}{ Religion } & Hindu & $79(83.2)$ & $72(82.8)$ & $4(80)$ & $3(100)$ \\
\hline & Kirat & $6(6.3)$ & $6(6.9)$ & $0(0)$ & $0(0)$ \\
\hline & Buddhist & $2(2.1)$ & $2(2.3)$ & $0(0)$ & $0(0)$ \\
\hline & Christian & $6(6.3)$ & $5(5.7)$ & $1(20)$ & $0(0)$ \\
\hline & Muslim & $2(2.1)$ & $2(2.3)$ & $0(0)$ & $0(0)$ \\
\hline \multirow{3}{*}{\begin{tabular}{|l|} 
Socio- \\
economic \\
status
\end{tabular}} & Middle & $20(21.1)$ & $19(21.8)$ & $1(20)$ & $0(0)$ \\
\hline & Low middle & $41(43.2)$ & $37(42.5)$ & $1(20)$ & $0(0)$ \\
\hline & Low & $34(35.8)$ & $31(35.6)$ & $3(60)$ & $3(100)$ \\
\hline \multirow[t]{5}{*}{ Education } & Illiterate & $12(12.6)$ & $11(12.6)$ & $0(0)$ & 1 (33.3) \\
\hline & Primary & $35(36.8)$ & $30(34.5)$ & $3(60)$ & $2(66.7)$ \\
\hline & Up to SLC & $34(35.8)$ & $33(37.9)$ & $1(20)$ & $0(0)$ \\
\hline & Undergraduate & $12(12.6)$ & $11(12.6)$ & $1(20)$ & $0(0)$ \\
\hline & Postgraduate & $2(2.1)$ & $2(2.3)$ & $0(0)$ & $0(0)$ \\
\hline \multirow[t]{4}{*}{ Occupation } & Employed & $45(47.4)$ & $42(48.3)$ & $2(40)$ & 1 (33.3) \\
\hline & $\begin{array}{l}\text { Now } \\
\text { unemployed }\end{array}$ & $12(12.6)$ & $12(13.8)$ & $1(20)$ & $0(0)$ \\
\hline & $\begin{array}{l}\text { Never } \\
\text { employed }\end{array}$ & $9(9.5)$ & $7(8)$ & $0(0)$ & 1 (33.3) \\
\hline & House-making & $29(30.5)$ & $26(29.9)$ & $2(40)$ & 1 (33.3) \\
\hline
\end{tabular}

The mean age of the patients with psychotic symptoms was $32.27 \pm 11.3$ years and the mean age at onset was $23.31 \pm 7.4$ years. There was a median delay of 0.17 years 
before making the first psychiatric contact at the mean age of $26.93 \pm 10.4$ years. Similarly there was a median delay of two years before the first hospitalization at the mean age of $29.35 \pm 11.0$ years. The median total duration of illness was six (range, 0-54) years. For the index episode the median duration of illness before presentation was 23 days (range, 1-365) and patients stayed in the hospital for a median duration of 20 (range, 1-70) days.

Table 2: Characteristics of hallucinations

(Sig=Significant at $p<0.05$, Chi-Square test, Mann Whitney test) $(n=95)$

\begin{tabular}{|c|c|c|c|c|c|c|c|}
\hline Characteristics & Category & $\begin{array}{l}\text { Total } \\
\text { n (\%) }\end{array}$ & $\begin{array}{c}\text { Manian } \\
\text { n (\%) }\end{array}$ & $\begin{array}{c}\text { Depression } \\
\text { n (\%) }\end{array}$ & $\begin{array}{c}\text { Mixed } \\
\text { n (\%) }\end{array}$ & $P$ value & Remarks \\
\hline \multirow[t]{2}{*}{\begin{tabular}{|l|} 
Hallucinations \\
\end{tabular}} & Present & $29(30.5)$ & $23(79.3)$ & $3(10.4)$ & $3(10.4)$ & 0.059 & \multirow[t]{2}{*}{ NS } \\
\hline & Absent & 66 (69.5) & $64(97)$ & $2(3)$ & $0(0)$ & & \\
\hline \multirow[t]{2}{*}{ Congruency } & Yes & $26(89.7)$ & $20(77.0)$ & $3(11.5)$ & $3(11.5)$ & 0.646 & \multirow[t]{2}{*}{ NS } \\
\hline & No & $3(10.3)$ & $3(100)$ & $0(0)$ & $0(0)$ & & \\
\hline \multirow[t]{2}{*}{ Content } & $\begin{array}{l}\text { No detail } \\
\text { available }\end{array}$ & $14(48.3)$ & $11(78.6)$ & $1(7.2)$ & $2(14.2)$ & & \multirow[t]{2}{*}{ NS } \\
\hline & $\begin{array}{l}\text { 2nd } \\
\text { person } \\
\text { without } \\
\text { command }\end{array}$ & 15(51.7) & $12(80.0)$ & $2(13.3)$ & $1(7.7)$ & 0.713 & \\
\hline \multirow[t]{2}{*}{ Visceral } & Present & $1(3.4)$ & $0(0)$ & $1(100)$ & $0(0)$ & 0.011 & \multirow[t]{2}{*}{ Sig } \\
\hline & Absent & $28(96.6)$ & $27(96.4)$ & $2(3.6)$ & $0(0)$ & & \\
\hline \multicolumn{2}{|c|}{$\begin{array}{l}\text { Median duration of } \\
\text { appearance } \\
\text { (IQR) (Min-Max) }\end{array}$} & $\begin{array}{l}10 \\
(29.00) \\
(1-20)\end{array}$ & $\begin{array}{l}9.00 \\
(29.00) \\
(3-65)\end{array}$ & $\begin{array}{l}11.59 \\
(21.00) \\
(1-9)\end{array}$ & $\begin{array}{l}30 \\
(60.00) \\
(30-90)\end{array}$ & 0.047 & Sig \\
\hline \multicolumn{2}{|c|}{$\begin{array}{|lr|}\text { Median duration of } \\
\text { disappearance } & (\mathrm{IQR}) \\
\text { (Min-Max) } & \end{array}$} & $\begin{array}{l}11.50 \\
(9.25) \\
(3-65)\end{array}$ & $\begin{array}{l}12.00 \\
(11.00) \\
(3-65)\end{array}$ & $\begin{array}{l}8.0 \\
(8.00) \\
(1-9)\end{array}$ & $\begin{array}{l}11.0 \\
(12.00) \\
(6-18)\end{array}$ & 0.222 & NS \\
\hline
\end{tabular}

Table 2 shows the hallucinations in the sample. It was present in 29 (30.5\%) cases. Of these $23(79.3 \%)$ were cases of mania, three $(10.3 \%)$ wee of depression, and three
(10.3\%) were of mixed episode. Twenty six cases $(89.7 \%)$ experienced mood congruent hallucination, and three mood incongruent hallucinations were seen in three mania 
cases. The content of the hallucination was second-person without command hallucination in 15 (51.7\%) while the content was not clear in rest of the cases. Visceral hallucination was experienced by only one depressive patient. The median duration of appearance of hallucination was 10 days (range, 1-20) for total sample in the index episode, 9 days (range, 1-120) for mania, 11.59 days (range, 5-26) for depression, and 30 days (range, 30-90) for mixed episode. Hallucinations disappeared after admission with a median duration of 11.5 days in the sample.

Table 3: Characteristics of delusions $(\mathbf{n}=95)$ (Sig=Significant at $p<0.05$, Chi-Square test)

\begin{tabular}{|c|c|c|c|c|c|c|c|}
\hline Characteristics & Category & $\begin{array}{l}\text { Total } \\
\text { n (\%) }\end{array}$ & $\begin{array}{c}\text { Mania } \\
\text { n (\%) }\end{array}$ & \begin{tabular}{|c|} 
Depression \\
$\mathrm{n}(\%)$
\end{tabular} & $\begin{array}{l}\text { Mixed } \\
\text { n (\%) }\end{array}$ & $P$ value & Remarks \\
\hline \multirow[b]{2}{*}{ Delusions } & Present & $77(81.1)$ & $73(94.8)$ & $2(2.6)$ & $2(2.6)$ & \multirow[t]{2}{*}{0.349} & \multirow[t]{2}{*}{ NS } \\
\hline & Absent & $18(18.9)$ & $14(77.8)$ & $3(16.7)$ & $1(5.6)$ & & \\
\hline \multirow[t]{2}{*}{ Persecutory } & Present & $15(19.5)$ & $11(73.3)$ & $2(13.3)$ & $2(13.3)$ & \multirow[t]{2}{*}{$<0.001$} & \multirow[t]{2}{*}{ Sig } \\
\hline & Absent & $62(80.5)$ & $62(100.0)$ & $0(0)$ & $0(0)$ & & \\
\hline \multirow[t]{2}{*}{ Grandiose } & Present & $66(93.5)$ & $\begin{array}{l}66 \\
(100.0)\end{array}$ & $0(0)$ & $0(0)$ & \multirow[t]{2}{*}{0.049} & \multirow[t]{2}{*}{ Sig } \\
\hline & Absent & $11(3.9)$ & $7(63.6)$ & $2(18.2)$ & $2(18.2)$ & & \\
\hline \multirow[t]{2}{*}{ Jealousy } & Present & $3(1.3)$ & $2(66.7)$ & $0(0)$ & $1(33.3)$ & \multirow[t]{2}{*}{0.003} & \multirow[t]{2}{*}{ Sig } \\
\hline & Absent & $74(96.1)$ & 71 (96.0) & $2(2.7)$ & $1(1.3)$ & & \\
\hline \multirow[t]{2}{*}{ Other } & Present & 1 (1.3) & $1(100.0)$ & $0(0)$ & $0(0)$ & \multirow[t]{2}{*}{0.973} & \multirow[t]{2}{*}{ NS } \\
\hline & Absent & $76(98.7)$ & 72 (94.7) & $2(2.6)$ & $2(2.6)$ & & \\
\hline
\end{tabular}

As displayed in Table 3, delusions were present in $77(81.1 \%)$ of cases of which 73 $(94.8 \%)$ were cases of mania and two $(2.6 \%)$ each of depression and mixed episode. Grandiose delusion was the most common delusion seen in 66 (93.5\%) cases, all of which were diagnosed as a manic episode. This was followed by persecutory delusion present in 15 (19.5\%) cases, eleven of which
$(73.3 \%)$ were cases of mania and two (13.3\%) each were of depression and mixed episode. Delusion of jealously was seen in three cases, two in mania and one in mixed episode. Other delusion was present in one case of mania, which was a bizarre delusion, however, this delusion was present only during this episode and fell short of duration criteria to warrant a diagnosis of 
schizoaffective disorder. In nine cases, the delusions persisted at the time of discharge; eight cases were mania and a case of depression (not shown in table).

Table 4: Association between hallucination and delusion $(\mathrm{Sig}=$ significant at $\mathrm{p}<0.05$, Chi-Square test)

\begin{tabular}{|l|l|l|l|l|l|}
\hline Characteristic & Category & \multicolumn{2}{|c|}{ Hallucinations } & $\begin{array}{c}\text { P value } \\
\text { n (\%) }\end{array}$ & Remarks \\
\hline & & Present $(\mathrm{N}=29)$ & Absent(N=66) & & \\
\hline Delusions & Present & $11(55)$ & $9(45)$ & 0.007 & Sig \\
\hline Persecution & Present & $6(40)$ & $9(60)$ & 0.385 & NS \\
\hline Grandiose & Present & $6(9.1)$ & $60(90.9)$ & $<0.001$ & Sig \\
\hline Jealousy & Present & $2(66.7)$ & $1(33.3)$ & 0.162 & NS \\
\hline Other & Present & $1(1.5)$ & $66(98.5)$ & $<0.001$ & Sig \\
\hline
\end{tabular}

As shown in table 4 , in 11 (55\%) cases, the delusion occurred along with hallucinations while in nine (45\%) cases, delusions occurred without hallucinations. The finding showed a high significance indicating that presence of hallucination was strongly associated with delusions. Of the different types of delusion, a significant association was seen with grandiose delusion and other delusions, with large proportion of these occurring in the absence of hallucination.

\section{Discussion}

In two years, there were total of 229 complete files of bipolar patients which were analysable. One hundred and fourteen patients had the presence of psychotic symptoms during their lifetime (49.8\%) which is lower than the 238 (68\%) out of 352 patients studied by Keck and his team. ${ }^{7}$ However, there were only 95 patients who had psychosis in the index episode (41.5\%). Our finding falls somewhere between $20-50 \%$ as described by Keck et al. in adults with bipolar disorder, ${ }^{7} 16-88 \%$ as described by Kowatch et al. in children and adolescents, ${ }^{8}$ $10-87 \%$ as described by Pavuluri et al. in paediatric bipolar disorders. ${ }^{9}$ Eighty seven $(91.63 \%)$ patients with mania had psychosis in our study. The preponderance of mania among the psychotic bipolar disorder is similar to that reported by Black and Nasrallah. $^{10}$

Almost one third patients had hallucinations in our study. In a review article about auditory verbal hallucinations in bipolar and major 
depressive disorder, the prevalence of hallucinations ranged from $11.3-62.8 \% .{ }^{11}$ Our findings of more auditory hallucinations in mania $(79.3 \%$ in mania, $10.4 \%$ each for bipolar depression and mixed episode) is in agreement with the findings of Black and Nasrallah ${ }^{10}$ but contrast with another study in which there were more in mixed episode $(22.9 \%)$ than mania (11.2\%) and depression (10.5\%) among 4972 hospitalized patients. ${ }^{12}$ Our study confirms that the most common hallucination in bipolar disorder is auditory and especially auditory verbal hallucinations. ${ }^{7,9,12,13}$ It was found in a study (30 affective psychosis and 30 schizophrenia) that $43 \%$ of patients with affective psychosis had second-person auditory hallucination which is broadly similar to our findings of 15 patients (51.7\%) reporting second-person auditory hallucinations. ${ }^{14}$ More patients with mania had early emergence of hallucination compared with bipolar depressed or mixed episode in our study reaching a significance level. Abrupt or acute onset of illness in mania might be a reason for early emergence of hallucination compared with depression.

Delusions were more common than hallucinations in our study. Among delusions, grandiose delusions were present in 66 $(93.5 \%)$ as the commonest delusion and present only in cases of mania. It was followed by persecutory delusion (19.5\%) and delusion of jealousy (1.3\%). In a study of 257 children aged 6-16 years, the frequency of grandiose delusion was found to be $67.7 \%{ }^{15}$ and in another study $79.3 \%,{ }^{13}$ however, in the study by Black and Nasrallah the persecutory delusion was the commonest being present in 148 out of 238 patients (62\%) followed by grandiose delusion (61\%). ${ }^{10}$ The finding of the latter study that delusion was more common in mania than in bipolar depression is similar to our study.

Both delusions and hallucinations were present in cases in our sample. The significant association of delusion with hallucination and the least association of delusion of grandiosity also confirms the findings of Baethge and his team. ${ }^{12}$

One of the major limitations of the study is its retrospective nature. The psychotic symptoms described here reflect the clinical judgement of the attending faculty of psychiatry rather than findings based on the structured instruments. Additionally it only reflects the finding in in-patients of bipolar disorder with psychotic symptoms.

In conclusion: psychosis is common in bipolar disorder. Grandiose delusions are the most common delusion and are relatively independent of hallucination. Delusions and hallucinations are generally associated. The auditory verbal hallucinations are the most common type of hallucination. Hallucinations in mania tend to come earlier than in bipolar depression and mixed episode, and most of 
the hallucinations in bipolar disorder are mood congruent.

\section{References}

1. American Psychiatric Association. Diagnostic and Statistical Manual of mental disorders. $5^{\text {th }}$ ed. (Special Indian Edition) New Delhi: CBS Publishers \& Distributors; 2013.

2. Pope HJ, Lipinski JJ. Diagnosis in schizophrenia and manic-depressive illness. A reassessment of the specificity of "shizophrenic" symptoms in the light of current research. Arch Gen Psychiatry 1978;38:811-28.

3. Tohen $M$, Waternaux $C$, Tsuang $M$. Outcome in mania. A 4-year prospective follow-up of 75 patients utilizing survival analysis. Arch Gen Psychiatry 1990;47:1106-11.

4. Winokur G, Scharfetter C, Angst J. A family study of psychotic symptomatology in schizophrenia, schizoaffective disorder, unipolar depression, and bipolar disorder. Eur Arch Psychiatry Neurol Sci 1985;234(5):295-8.

5. Craney JL, Geller B. A prepubertal and early adolescent bipolar disorder-I phenotype: review of phenomenology and longitudinal course. Bipolar Disord 2003;5(4):243-56.

6. Bhangoo RK, Dell ML, Towbin K,
Myers FS, Lowe $\mathrm{CH}$, Pine DS, et al. Clinical correlates of episodicity in juvenile mania. $J$ Child Adolesc Psychopharmacol 2003;13(4):507-14.

7. Keck PE, McElroy SL, Havens JR, Altshuler LL, Nolen WA, Frye MA, et al. Psychosis in bipolar disorder: Phenomenology and impact on morbidity and course of illness. Compr Psychiatry 2003;44(4):263-9.

8. Kowatch RA, Youngstrom EA, Danielyan A, Findling RL. Review and meta-analysis of the phenomenology and clinical characteristics of mania in children and adolescents. Bipolar Disord 2005;7(6):483-96.

9. Pavuluri MN, Herbener ES, Sweeney J A. Psychotic symptoms in pediatric bipolar disorder. J Affect Disord 2004;80(1):19-28.

10. Black DW, Nasrallah A. Hallucinations and delusions in 1,715 patients with unipolar and bipolar affective disorders.

Psychopathology 1989;22(1):28-34.

11. Toh WL, Thomas N, Rossell SL. Auditory verbal hallucinations in bipolar disorder (BD) and major depressive disorder (MDD): A systematic review. J Affect Disord. Elsevier; 2015;184:1828.

12. Baethge $\mathrm{C}$, Baldessarini RJ, Freudenthal K, Streeruwitz A, Bauer 
M, Bschor T. Hallucinations in bipolar disorder: characteristics and comparison to unipolar depression and schizophrenia. Bipolar Disord 2005;7(2):136-45.

13. Pini S, de Queiroz V, Dell'Osso L, Abelli M, Mastrocinque C, Saettoni $M$, et al. Cross-sectional similarities and differences between schizophrenia, schizoaffective disorder and mania or mixed mania with mood-incongruent psychotic features. Eur Psychiatry 2004;19(1):8-14.
14. Kumari R, Chaudhury $\mathrm{S}$, Kumar $\mathrm{S}$. Dimensions of hallucinations and delusions in affective and nonaffective illnesses. ISRN Psychiatry 2013;2013:616304.

15. Tillman R, Geller B, Klages T, Corrigan M, Bolhofner K, Zimerman B. Psychotic phenomena in 257 young children and adolescents with bipolar I disorder: delusions and hallucinations (benign and pathological). Bipolar Disord 2008;10(1):45-55. 